\title{
FINDING THE BEST LOCATIONS FOR FURROWS IN SOIL BERMS OF DRAINAGE DITCHES USING LIDAR DATA
}

\begin{abstract}
Janis IVANOVS, Latvian State Forest Research Institute "Silava". Address: 111 Rigas street, Salaspils, LV-2169 Latvia; janis.ivanovs@silava.lv (corresponding author)

Raitis MELNIKS, Latvian State Forest Research Institute "Silava”. Address: 111 Rigas street, Salaspils, LV-2169 Latvia; raitis.melniks@silava.lv

Soil berms are typically built on the sides of ditches and are designed to purify water from agricultural fertilizers and to limit the transport of sediments to water bodies. However, for soils with fine particles, water filtration is limited and wet soil conditions can occur, which in turn reduces the soil's hydrologic conductivity capacity and hinders tree growth in the forest. The aim of the study is to develop a methodology for automatic modeling of the furrows in soil berms. Open source software QGIS and GRASS GIS is used in data processing. LiDAR data with minimum ground point density of 1.5 points per square meter were used in DEM creation. Local maximum analysis and further data filtration were used in determination of locations of soil berms. The results show that by making one furrow for every $185 \mathrm{~m}$ of ditches it is possible to reduce the area of the depressions by up to $91.8 \%$.
\end{abstract}

Keywords: depressions, wet areas, improved water regime.

\section{INTRODUCTION}

Soil berms by drainage ditches are typically built as a by-product of ditch excavation or cleaning and are typically 3-4 m wide (Appelboom, Chescheir, Skaggs, \& Hesterberg, 2002). In agricultural lands, soil berms are designed to protect water bodies from the leaching of nitrogen and pesticides as they block surface runoff. When water enters a ditch or canal, it first passes through the soil layer and is purified (Diaz, Lang, Daroub, \& Chen, 2015). Forest buffer strips also serve as a place to purify water from nitrogen, phosphorus and other elements. In these areas, it is preferable for water to flow in diffused form rather than concentrating in streams. Thus, depending on soil characteristics and riparian zone tree species composition, it is possible to capture up to $70 \%$ of all sediments and nutrients initially flowing into the buffer zone (Wallace et al., 2018).

Soil berms of drainage ditches in forest usually should be made on the lowest side of the ditch, so it doesn't hinder water runoff. One year after making soil berm it should be leveled so it doesn't exceed $1 \mathrm{~m}$ in thickness and it can afterwards be used as access road (Zalitis, 2003). In forests growing on clayey and moraine sediments, soil berms may contribute to increased water accumulation in the forest stand due to the low water conductivity for such soils. Wet soil conditions may be a challenge in forestry (McNabb, Startsev, \& Nguyen, 2001) and can involve various risks such as reduced soil bearing capacity, tree root death, etc. (Christensen et al., 1996; Zālītis, 2012). It may also lead to increased risk of rutting and soil compaction during forestry operations (Han, Han, Page-Dumroese, \& Johnson, 2009). In most cases in the forest the effects of mechanical barriers are undesirable because of formation of anaerobic conditions in the soil and deterioration of forest growth. In order to prevent water accumulation in the forest stand, the soil berms are crossed with deep furrows, which drain excess water and improve soil aeration. The aim of this study was to develop a methodology for automatic modeling of placement of the furrows cutting through the soil berms. LiDAR data were used because of accurate representation of local terrain.

\section{MATERIALS AND METHODS}

The research area is located in Ceraukste parish and covers $25 \mathrm{~km}^{2}$ of area, of which $11.3 \mathrm{~km}^{2}$ is covered by forest (Figure 1). The predominant type of Quaternary sediments in the study area is silty clay and silty moraine (Meirons, 2002). The area has an extensive drainage system and both mineral and peat soils are drained. The dominant forest types are Myrtillosa turf. mel., Mercurialosa mel., Myrtillosa mel., and Aegipodiosa. Total length of ditches exceeds $170 \mathrm{~km}$.

All data processing is done in open source GIS software QGIS 3.4. and Grass GIS 7.8.1. A DEM (Digital Elevation Model) with a resolution of $1 \mathrm{~m}$ has been created for the study area using LiDAR (Light detection and ranging) data maintained by the Latvian Geospatial Information Agency. The work process was performed in the Latvian

Copyright (C) 2019 The Authors. Published by Vytautas Magnus University. This is an open-access article distributed under the terms of the Creative Commons Attribution License (CC BY 4.0), which permits unrestricted use, distribution, and reproduction in any medium, provided the original author and source are credited. 
coordinate system LKS-92 EPSG: 3059 . The vector data format used is *.shp, while raster files use *.tif (Temporary files created using SAGA GIS tools also use *.SDAT format).

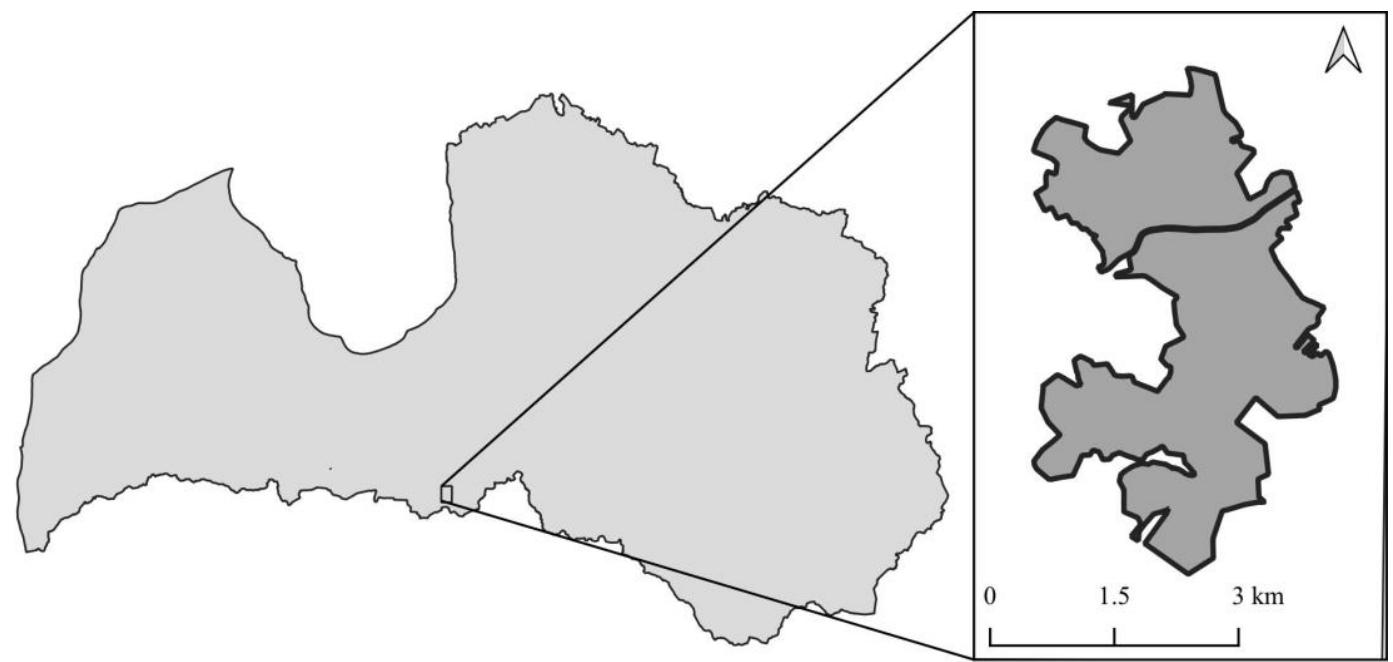

Figure 1. Study area

During this study we assume that all the existing ditches in the area are functional and the water that enters them is drained from the environment. Soil berms are detected using the method of nearest neighbor analysis using sliding window principle which determines locally elevated areas that at least $0.2 \mathrm{~m}$ above neighboring areas. Thereafter, locally elevated areas that are $10 \mathrm{~m}$ or further away from the axis of the ditches are filtered out. Additionally, the locally elevated areas that are not stretched out are filtered by area / perimeter ratio and for locally elevated area to be counted as soil berm, ratio should be less than 0.8 .

Manipulations have been made to determine the optimum location of the furrows within the areas of existing soil berms. Gaps of less than $4 \mathrm{~m}$ between two existing soil berm fragments have been filled and all soil berm area has been artificially raised above the maximum height in a given area by the DEM raster calculator, resulting in a modified "DEM with elevated soil berms". An additional DEM modification has been created, where raster values have been replaced by Null at soil berm locations. This raster layer is designed to define a natural stream network, assuming that the stream may occur if its catchment area is larger than $5000 \mathrm{~m}^{2}$.

All modified DEM layers were processed using Fill Sinks (Wang \& Liu) algorithm (Wang \& Liu, 2006). The filled version of "DEM with elevated soil berms" was further processed to find deepest points of depressions using the sliding window principle with a radius of 15 cells. All of the depressions larger than $100 \mathrm{~m}^{2}$ at the depth of $5 \mathrm{~cm}$ were vectorized and further filtered, so only depressions with deepest parts within $25 \mathrm{~m}$ from axis of ditches were analyzed. The remaining centers of the depressions are connected in a single layer with the end points of the natural streams and connected in a straight line with the ditch axes. These connection lines indicate the optimum locations for the furrow locations (

Figure 2).

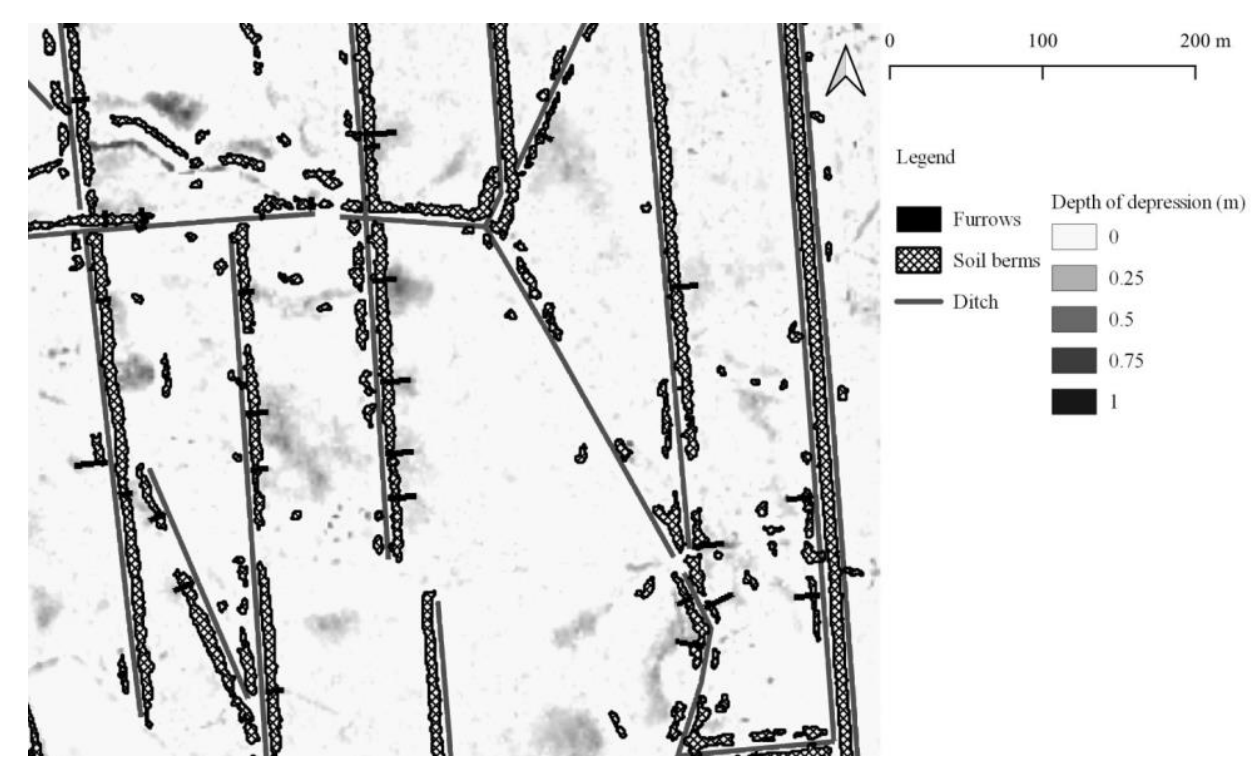


Figure 2. Graphical modeling results

Another modification of the DEM is made, where the values of the original DEM overlapping with ditch axes and modeled furrows are replaced by Null. It is thus assumed that when water enters a ditch or furrow, it is drained from the environment. The newly created DEM modification has been processed with Fill Sinks (Wang \& Liu) algorithm and remaining depressions are mapped.

\section{RESULTS AND DISCUSSION}

The original area of depressions is taken from a situation where furrows are intuitively made by excavator or other machine operator (Original DEM), while the final result is based on modeling results using high-resolution terrain data. The obtained results indicate a significant decrease in the depression areas after data processing (Figure 3 ). In total 544 depressions have been affected by modeled furrows and changes in area are represented by black dots in graph below. More than $25 \%$ of the pre-defined depressions have disappeared completely and their total area has decreased by $91.8 \%$.

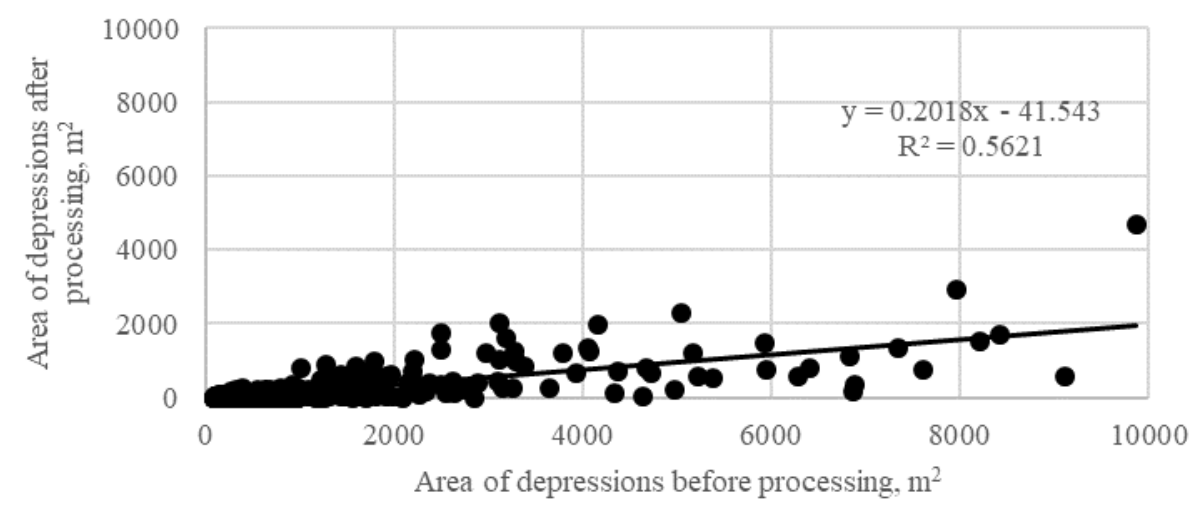

Figure 3. Area of depressions before and after modeling

There are no correlation between the size of original depression and effectiveness of used method. Figure 4 shows the percentage reduction of the depressed area relative to their original size and the coefficient of determination is very low. A total of 936 furrows were modeled for a total ditch length of $173.5 \mathrm{~km}$ or on average one furrow every 185 $\mathrm{m}$. By using the developed method and the data-based approach, it is possible to efficiently plan the locations of the furrows, thus improving the tree growth conditions in the forest. The use of LiDAR data provides an opportunity to evaluate the effectiveness of each modeled furrow and its affected area, thus providing an opportunity to assess the need for a furrow at each specific site.

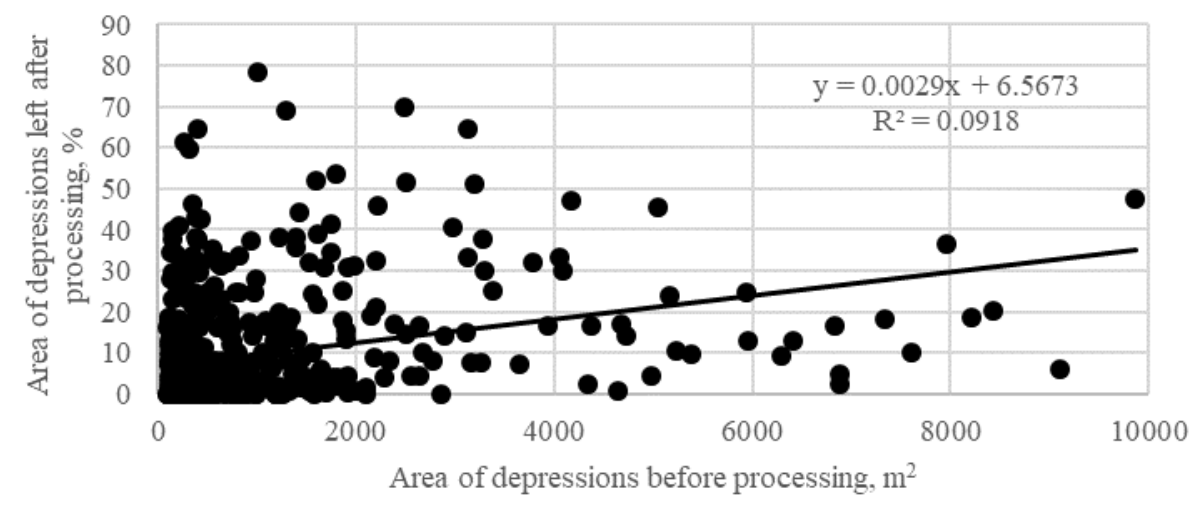

Figure 4. The relationship between the size of the depression and the possible reduction in size

\section{CONCLUSIONS}

Open GIS tools allow modeling of the optimum locations of furrows in the soil berms by drainage ditches, thereby achieving a reduction of the area of adjoining depressions by up to $91.8 \%$.

The initial depression area is irrelevant to drainage efficiency because there are no correlation between size of depression before and after data processing.

The developed methodology can be used for planning of locations for furrows on existing soil berms, as well as when planning new ditch objects. 
ACKNOWLEDGEMENTS. The study was implemented within the scope of the Forest Sector Competence Centre of Latvia - No. 1.2.1.1/18/A/004 P11, Elaboration of guidelines and modeling tool for greenhouse gas (GHG) emission reduction in forests on nutrientrich organic soils"

\section{REFERENCES}

1. Appelboom, T. W., Chescheir, G. M., Skaggs, R. W., \& Hesterberg, D. L. 2002. Management practices for sediment reduction from forest roads in the coastal plains. Transactions of the ASAE, Vol. 45(2). https://doi.org/10.13031/2013.8529

2. Christensen, N. L., Bartuska, A. M., Brown, J. H., Carpenter, S., D’Antonio, C., Francis, R., Woodmansee, R. G. 1996. The Report of the Ecological Society of America Committee on the Scientific Basis for Ecosystem Management. Ecological Applications, Vol. 6(3), pp. 665-691. https://doi.org/10.2307/2269460

3. Diaz, O. A., Lang, T. A., Daroub, S. H., \& Chen, M. Q. 2015. Best Management Practices in the Everglades Agricultural Area: Controlling Particulate Phosphorus and Canal Sediments 1. Retrieved from https://www.semanticscholar.org/paper/BestManagement-Practices-in-the-Everglades-Area\%3A-1-Diaz-Lang/2961cda9436f7b128657bdabeaf1c6572fdeac14

4. Han, S.-K., Han, H.-S., Page-Dumroese, D. S., \& Johnson, L. R. 2009. Soil compaction associated with cut-to-length and wholetree harvesting of a coniferous forest. Canadian Journal of Forest Research, Vol. 39(5), pp. 976-989. https://doi.org/10.1139/X09$\underline{027} \mathrm{v}$

5. McNabb, D. H., Startsev, A. D., \& Nguyen, H. 2001. Soil Wetness and Traffic Level Effects on Bulk Density and Air-Filled Porosity of Compacted Boreal Forest Soils. ResearchGate, Vol. 65(4). https://doi.org/10.2136/sssaj2001.6541238x

6. Meirons, Z. 2002. Kvartāra nogulumi. M.:1:200 000. Valsts ǵeologijas dienests.

7. Wallace, C., McCarty, G., Lee, S., Brooks, R., Veith, T., Kleinman, P., \& Sadeghi, A. 2018. Evaluating Concentrated Flowpaths in Riparian Forest Buffer Contributing Areas Using LiDAR Imagery and Topographic Metrics. Remote Sensing, Vol. 10(4), pp. 614. https://doi.org/10.3390/rs10040614

8. Wang, L., \& Liu, H. 2006. An efficient method for identifying and filling surface depressions in digital elevation models for hydrologic analysis and modelling. International Journal of Geographical Information Science, Vol. 20(2), pp. $193-213$. https://doi.org/10.1080/13658810500433453

9. Zalitis, P. 2003. Soil Berm. In Encyclopedia of Forest (Broks, J, pp. 33). Zelta Grauds. Retrieved from https://www.letonika.lv/groups/default.aspx?cid=35681\&r=7\&lid=35681\&q=\&h=0

10. Zālīitis, P. 2012. Mežs un ūdens. Salaspils: LVMI Silava. 